\section{Frequency and phenotypic consequences of the 3199del6 CFTR mutation in French Canadians}

To the Editor:

The observation of healthy individuals bearing a severe cystic fibrosis (CF) mutation and I148T in trans but not carrying the 3199del6 mutation has suggested that I148T is not a CF-causing mutation. ${ }^{1,2}$ Moreover, 3199del6-positive CF patients lacking
I148T, compound heterozygous with another CF mutation, indicate that $3199 \mathrm{del} 6$ is the disease-causing mutation in the complex allele I148T-3199del6. ${ }^{2,3}$ Here, we report on the 3199del6 testing results in our cohort of I148T-positive individuals, the frequency of this deletion in the French Canadian population, as well as the phenotype of our 3199del6-positive patients.

The presence of the 3199del6 mutation was determined in a cohort of 32 I148T-positive samples: 27 unrelated CF French Canadian patients, referred for corroboration of CF diagnosis, and 5 carriers ( 3 French Canadians, 1 Lebanese, and 1 adopted of unknown origin). The presence of the 3199del6 mutation was tested by PCR-based heteroduplex analysis, using primers h17ai5 (5'-AATCACTGACACACTTTGTCCACTT-3') and h17ai3 (5'TCAAATAGCTCTTATAGCTTTTTTACAAGATG-3') for amplification of CFTR exon $17 \mathrm{a} .{ }^{4}$ The presence of the deletion was confirmed by BigDye terminator cycle sequencing in an ABI 310 genetic analyzer. All 27 patients carried the 3199 del 6 mutation (Table 1). The phase of I148T and 3199del6 was verified in 17 patients and, in all (100\%), both variants occurred in cis (I148T3199del6 complex allele). Of the patients referred for carrier status determination, the three French Canadians also carried the deletion, whereas the two others, one Lebanese and one of unknown origin, did not.

We next determined the frequency of the complex allele I148T3199del6 in our cohort of 202 unrelated CF French Canadian patients (404 CF chromosomes) analyzed since January 2000. In this cohort, it accounts for $2.2 \%$ of CF alleles, whereas the two major mutations, F508del and $621+1 \mathrm{G}>\mathrm{T}$ account for $69.5 \%$ and $5.4 \%$, respectively, as expected for this population. This I148T-3199del6 frequency is in contrast to the previously reported I148T frequency of 9.1\% in French Canadians. ${ }^{5}$ Explanations for this frequency discrepancy could be as follows: a sample bias, because we receive patients from all Quebec regions and the previous report analyzed only French Canadians from the Quebec City area; or more likely, that the $2.2 \%$ reflects the frequency of the real CF-causing mutation, 3199del6, in French Canadians, which in this population complexes in cis with I148T, whereas $9.1 \%$ corresponds to the I148T polymorphism frequency. Unfortunately, the Quebec City cohort was not available for testing for the presence of the 3199del6 mutation.

We then ascertained the correlation between 3199del6 and CF phenotype in our 27 unrelated CF French Canadian patients. Clinical data, which included sweat test $(\mathrm{Cl})$ values, respiratory and pancreatic status, age of diagnosis, and ethnicity, were provided by physicians, nurses, or genetic counselors following these patients (Table 1). As expected, a pancreatic insufficiency (PI) phenotype was observed in 21 of 22 patients bearing 3199del6 and another severe CF allele (F508del, I507del, N1303K, or $621+1 \mathrm{G}>\mathrm{T}$ ). We could not draw any conclusions for one patient due to insufficient clinical data. In only one patient (F508del/I148T-3199del6) was a pancreatic sufficiency phenotype observed. A pancreatic sufficiency phenotype was found in two patients carrying $\mathrm{A} 455 \mathrm{E}$ on the second allele, consistent with the previously reported association of A455E with a mild CF phenotype. ${ }^{6}$ In two patients, a second CF-causing mutation was not identified despite the use of a 35 
Table 1

Genotype-phenotype correlation of CF patients bearing the complex allele I148T-3199del6

\begin{tabular}{|c|c|c|c|c|c|c|}
\hline Genotype & $\begin{array}{c}\text { No. of } \\
\text { patients }\end{array}$ & $\begin{array}{c}\text { Age } \\
(\mathrm{y})\end{array}$ & $\begin{array}{l}\text { Pancreatic } \\
\text { status }\end{array}$ & $\begin{array}{c}\text { Sweat } \\
\text { test }\end{array}$ & $\begin{array}{c}\text { Age at } \\
\text { diagnosis }\end{array}$ & Ethnicity \\
\hline F508del/I148T-3199del6 & 18 & 3 to 31 & PI & 88 to 154 & Birth to $12 \mathrm{y}$ & Fr Cdn \\
\hline I507del/I148T-3199del6 & 1 & 4 & PI & 106 & 2 months & Fr Cdn \\
\hline $621+1 \mathrm{G}>\mathrm{T} / \mathrm{I} 148 \mathrm{~T}-3199 \mathrm{del} 6$ & 1 & & PI & 105 & & Fr Cdn \\
\hline N1303K/I148T-3199del6 & 1 & 35 & PI & & 18 months & Fr Cdn \\
\hline F508del/I148T-3199del6 & 1 & 24 & PS & 142 & 4 months & Fr Cdn \\
\hline A455E/I148T-3199del6 & 2 & $23 / 55$ & PS & 130 & $16 / 20 y$ & Fr Cdn \\
\hline I148T-3199del6/Unk. Mut. & 1 & 5 & PI & 108 & 3 months & Fr Cdn \\
\hline I148T-3199del6/Unk. Mut. & 1 & & & & & Fr Cdn \\
\hline F508del/I148T-3199del6 & 1 & & & & & Fr Cdn \\
\hline
\end{tabular}

PI, pancreatic insufficiency; PS, pancreatic sufficiency; Fr Cdn, French Canadian.

mutation panel, which included the 25 ACMG recommended mutations. Twenty-one patients demonstrated evidence of recurrent pulmonary infections by Pseudomonas aeruginosa and/or Staphylococcus aureus, typical of CF. Altogether, our observations further demonstrate that the 3199del6 mutation is associated with a classical pancreatic insufficiency CF phenotype, consistent with the suggestion of Buyse et al. ${ }^{7}$

Previous studies have identified 3199del6 in 1.8\%, 0.9\%, and $0.6 \%$ of I148T heterozygous carriers and determined the frequency of 3199del6 in the general North American population to be $<0.1 \%$, below the frequency threshold criteria for inclusion in the ACMG CF mutation screening panel. ${ }^{1,8,9}$ In this study, we report a 2.2\% frequency for the 3199del6 mutation among French Canadian CF chromosomes. As mentioned, only two I148T carriers (one Lebanese and one of unknown origin) tested negative for the 3199del6 mutation in our cohort of 32 unrelated I148T individuals. In other words, in our samples, all I148T French Canadian alleles also had the 3199del6 mutation, probably reflecting a founder effect, and justifying its inclusion in routine CF testing/ screening in this ethnic group.

In conclusion, our study demonstrates that the 3199del6 mutation is associated with a classical pancreatic insufficiency CF phenotype and accounts for $2.2 \%$ of French Canadian CF chromosomes. The 2004 ACMG mutation panel revision recommends exclusion of I148T from the CF mutation panel. ${ }^{10}$ However, in the French Canadian population, I148T testing must be replaced by 3199del6 testing, which can be done using a simple PCR-based heteroduplex assay. If I148T testing is continued, then the data presented here strongly support 3199del6 testing for every I148T-positive result.

Andrea Frota Ruchon, $M D, P h D$, Shannon R. Ryan, MS, Raouf Fetni, PhD, Rima Rozen, PhD, Patrick Scott, PhD

Molecular Genetics Laboratory

The Montreal Children's Hospital Montreal, Quebec

\section{References}

1. Rohlfs EM, Zhou Z, Sugarman EA, Heim RA, Pace RG, Knowles MR et al. The I148T CFTR allele occurs on multiple haplotypes: a complex allele is associated with cystic fibrosis. Genet Med 2002;4:319-323.

2. Strom CM, Huang D, Buller A, Redman J, Crossley B, Anderson B et al. Cystic fibrosis screening using the College panel: platform comparison and lessons learned from the first 20,000 samples. Genet Med 2002;4:289-296.

3. Claustres M, Altieri JP, Guittard C, Templin C, Chevalier-Porst F, Des Georges M. Are p.I148T, p.R74W and p.D1270N cystic fibrosis causing mutations? BMC Med Genet 2004;5:19.

4. Le Marechal C, Audrezet MP, Quere I, Raguenes O, Langonne S, Ferec C. Complete and rapid scanning of the cystic fibrosis transmembrane conductance regulator (CFTR) gene by denaturing high-performance liquid chromatography (D-HPLC): major implications for genetic counselling. Hum Genet 2001;108:290-298.

5. The Cystic Fibrosis Genetic Analysis Consortium: Population variation of common cystic fibrosis mutations. Hum Mutat 1994;4:167-177.

6. De Braekeleer M, Allard C, Leblanc JP, Simard F, Aubin G. Phenotype correlation in cystic fibrosis patients compound heterozygous for the A455E mutation. Hum Genet 1997;101:208-211.

7. Buyse IM, McCarthy SE, Lurix P, Pace RP, Vo D, Bartlett GA et al. Use of MALDITOF mass spectrometry in a 51-mutation test for cystic fibrosis: Evidence that 3199del6 is a disease-causing mutation. Genet Med 2004;6:426-430.

8. Buller A, Olson S, Redman JB, Hantash F, Chen R, Strom CM. Frequency of the cystic fibrosis 3199del6 mutation in individuals heterozygous for I148T. Genet Med 2004;6:108-109.

9. Monaghan KG, Highsmith WE, Amos J, Pratt VM, Roa B, Friez M et al. Genotypephenotype correlation and frequency of the 3199del6 cystic fibrosis mutation among I148T carriers: Results from a collaborative study. Genet Med 2004;6:421425.

10. Watson MS, Cutting GR, Desnick RJ, Driscoll DA, Klinger K, Mennuti M et al. Cystic fibrosis population carrier screening: 2004 revision of American College of Medical Genetics mutation panel. Genet Med 2004;6:387-391. 